\title{
Relevant Problems Associated with the Regional Geoecology, Geosituational Mapping and Modelling Experience in the Kaliningrad Region
}

\author{
Evgeny V. Krasnov* \\ Galina M. Barinova \\ Sergey I. Zotov \\ Immanuel Kant Baltic Federal University, Russian Federation \\ *Corresponding Email: EKrasnov@kantiana.ru
}

\section{Doi:10.5901/mjss.2015.v6n6s7p154}

\begin{abstract}
The study examines the recent trends in the mapping and modelling of regional geoecological and geosituational situation. The manuscript is based on analysing the techniques being applied for research of the local and regional geosituations in different years gained by geographers, geologists and geo-environmentalists representing Kaliningrad universities and academic institutions as well as their colleagues from the neighbouring research and industrial organisations in Lithuania and Poland, while providing the subsequent critical assessment of the findings.
\end{abstract}

Keywords: Kaliningrad region, regional geoecology, geosituational mapping

\section{Introduction}

To somebody, who does not have the knowledge base in the above topics, the 'environmental' issues in Russia's exclave region on the Baltic Sea seem to have remained persistently unchanged since the Immanuel Kant time, and they pertain to the unavailability of a municipal sewage system, air pollution by motor vehicles, an increase in the number of unauthorised dumpsites, the amount of industrial waste, etc. One can depict another image of the geo-environmental situation by going through the state Reports on the Environmental Situation in the Kaliningrad region published annually (State Reports..., 2011, 2012, 2013). It clearly follows that the air quality in the region's cities is satisfactory, and the 'environmental' contamination level is even lower than the Russian Federation's average as a whole.

It is well known that 'statistics' can do everything but in this case when it is not only and not so much about the pollution of various life-supporting 'environment' but about the complex interlocking relationships in the 'nature - economic activity - man' system, some more powerful research tools, methods and technologies need to be used for making research-backed findings, conclusions and recommendations. These methodological tools in the hands of a geographer, a geologist, an oceanologist primarily include a variety of techniques and methods for mapping and modelling of the processes taking place in the regional geosystems under the influence of natural and anthropogenic factors. The systemic transformation of the land and water geosystems is caused not so much by the factors of geosphere shells external to human beings, on the contrary, and it is definitely related to the so-called 'human factor'.

Mapping models enable to 'grasp' not only the spatial geosituation differentiation, which is rather volatile, and it often has indistinctly pronounced contours and boundaries but in the comparison of asynchronical series between themselves, a chronological focus (trend) of the transformation processes is determined, the process frequency (i.r. cyclical nature). This in turn, opens up new geo-environmental forecasting possibilities, also the forecasts concerning the occurrence and development of geo-environmental situations that may be adverse to the leading 'actor' including the critical and catastrophic ones.

This review summarises the experience in mapping and modelling of the local and regional geosituations in different years gained by geographers, geologists and geo-environmentalists representing Kaliningrad universities and academic institutions as well as their colleagues from the neighbouring research and industrial organisations in Lithuania and Poland. 


\section{Methodology of Cartographic Modelling the Geosituations}

Initially, in the 1980s - 1990s of the XX century, the regional geo-ecological research was considered to be the chemical and analytical study of the distribution of contaminants in the Baltic Sea and adjacent land. Based on the materials of marine expeditions, identified were the most polluted areas of water and storm water above the dockside dumpsites, in the apexes of bays, lagoons and estuaries (Yemelyanov, 1993; Barinova et al., 1994). One of the unexpected results of that period should include the detection of elevated silver concentrations in the sediments of the Gotland Basin, although it later turned out that there was a precious metal potential (Ag, Au) in the adjacent land (Blazchishin, \& Krasnov, 1998; Zagorodnykh, 2001). To depict a complete picture of the man-induced transformation of the coastal marine and continental geosystems obtained for metals and isotopes, there were not enough data, and in order to further improve the assessment of geosituations in connection with the economic activities, urban development and recreational development, some landscape planning and mapping methods needed to be used. As an example, let us consider the landscape ecological mapping experience on the Curonian Spit (Kozlovich, 2006). First of all, it is worth mentioning the contribution of the Lithuanian colleagues in the buildup and development of the activity area. Based on the detailed field surveys and geomorphological analysis of the territories, they made a map of the Vostochny Cape's landscape and the surrounding areas. On a small lagoon coastal area $\left(30 \mathrm{~km}^{2}\right)$ it was possible to identify 20 'simple urochisches' (natural landmarks) thereby demonstrating the fractional differentiated landscape structure of the Curonian Spit. The legend of the map includes meso- and microforms of relief, vegetation associations, soil varieties and even the leading geological and geomorphological processes, abrasion and accumulation. As a result, the origin and development of the landscape of the lagoon coast of the Curonian Spit, a unique seaside geosystem, now a World Heritage site, which is under the auspices of UNESCO, were described in detail on the cartographic basis. This experience, according to Kozlovich (2006), has not lost its significance in our days, and we should agree with that.

In 1967, thanks to the joint efforts of the landscape scientists of Lithuania and Kaliningrad, the first applied map (for the recreational development purposes) of landscape zoning with the justification of 19 natural and recreational districts was completed.

In the 1970's - 1980's of XX century the Curonian Spit is becoming a testing ground for complex interdisciplinary research under the direction of A.B. Basalikas. The key focus of these works is on spatial planning (multilateral deterministic land arrangement). In the same period a number of dedicated organisations from Moscow and Leningrad proceeded with design surveying on the Spit. The surveying and pre-surveying outcomes are only partially published (Stauskas, 1987; Basaliskas, 1921). They are limited to the identification of the landscape structure and preparation of large-scale landscape maps on that basis. The first fractional landscape zoning map was compiled. Its refined version with the identification of individual and typological categories of geographical landscapes was described by Kavalyauskas (1976).

In 1984-1986 the Soyuzgiproleskhoz Institute, Moscow performed design and development to arrange for the future area of the National Park Curonian Spit. Following the method of N.A. Solntseva (Moscow State University) and using the detailed expedition materials a synthetic landscape and morphological map in three versions (1:50 000, 1:25 $000,1: 10000$ ) was first created for the successive stages of the design. The first one features the types of stows (natural landmarks, in Russian "urochishche") united in groups, for the second and third stages of the design some types of stows and sub-stows are shown on the map. By the peculiarities of the natural conditions, the geographical areas are characterised by various types of stows.

Landscape maps provided the basis for the development of the land-use design layout of the National Park Curonian Spit, evaluation maps concerning the vulnerability of the recreational capacity, improvement of the local recreational areas, aesthetic and other aspects.

In those years, the Chair of Nature Conservation of the Kaliningrad State University participated actively in mapping some key areas including the areas of waterlogging, recreational development and others. According to the materials of the protected theses by L.V. Korneevets and I.I. Volkova made a landscape map of the southern part of the Curonian Spit first published in the atlas of the Kaliningrad region (Volkova, \& Korneevets, 2002).

At the beginning of the XXI century, in the National Park geographers and geoecologists of the Kaliningrad State University, after performing landscape and ecological monitoring of natural changes in vegetation using the integrated profiling techniques along with geobotanical surveying identified the diversity of the landscape facial structure (mosaic structure, contrast range, banding and patchiness).

It would be natural for the landscape and mapping activities on the Curonian Spit, as I.I. Kozlovich expected, to be completed by the creation of a large-scale landscape map with the use of remote sensing files and close RussianLithuanian support, a kind of the previous years' cooperation. You can only hope that this project will still be implemented 
sooner or later.

Both cartographic and digital models along with the empirical and statistical ones were useful to explore the spatial and temporal transformation of geosystems in more detail, identify the specificity of the interactions within them not only on the visually displayed multidimensional object processes but, in some cases, at the atomic and molecular level (lichenoindication of heavy metal aerosol fallout, concentration of substances, pollutants by soft tissues and shells of mollusks etc.). The researchers had the opportunity to multiply carry out an experiment with the repeated geosituations (for example, storm floods, hurricane winds etc.) and obtained data on the sea water levels and damage) and then develop various scenarios and models of the possible process development in the short and medium perspectives.

When some weaknesses inherent in any model are identified, they are corrected and re-tested empirically (numerical experiments in simulation modelling).

In recent years, the geoinformation approaches have become more common in the computer modelling of regional changes in natural and social systems thereby opening new greening horizons for the urban development through the implementation of programmes for landscape planning, placement of recreation sites and areas, development of transport systems. The importance of GIS technologies and innovative forecasting methods cannot be overestimated in the simulation of emergency geosituations (earthquakes, floods etc.).

By using GIS software packages Kaliningrad experts prepared a number of crisis development models for situations arising in the context of storm surges of sea water in river estuaries (Krasnov, \& Lyubimova, 2005; Krasnov, \& Lyubomova, 2013; Moskalets, \& Lyubomova, 2013). The geographic community included the Kaliningrad region's Geographic Atlas with the most significant outcomes in the field of digital mapping and environment and situation modelling on a regional scale (Geographical Atlas of the Kaliningrad Region, 2001). And they did the same with regard to the Kaliningrad region's Landscape Programme developed for the first time among the constituent territories of the Russian Federation (Dedkov, \& Fedorov, 2006). Both of these projects were implemented under the guidance of leading scientists of I. Kant BFU.

The region's Geographic Atlas includes more than 200 digital maps and other graphic characteristics of the physical-geographical, ecological-geographical and socio-geographical contents; the Landscape Programme is based on the evaluation maps and targeted maps of ecosystems, species and habitats in accordance with their importance and sensitivity to human-induced changes. Due to the density of population and development of the region's territory, in demonstrating feasibility of the action programme, its drafters cartographically presented the spatial differentiation of nature management conflicts, and with due allowance for them, the objectives of the environmentally oriented use of the protection and reproduction of the region's natural resource potential.

Based on atlas mapping and landscape planning, a detailed plan for the implementation of the priority and medium-term measures to optimise regional nature management pattern was drawn up; unfortunately it was not fulfilled during the following 10 years.

In a series of the Atlas of the World edition, to further develop cartographic models in our region, the cartographic materials reflecting the current state of the Kaliningrad region's natural resources, social and economic area, ecology and history were published in Volume 20 (World Atlas..., 2011).

Among the practical purposes for atlas mapping and modelling, their educational and pedagogical functions, which are of paramount importance for the younger generation of school and university teachers, should be emphasised.

To exemplify, considered below are some of the results of specific geo-ecological studies carried out in the name of the Immanuel Kant BFU at the level of doctoral and PhD theses.

\section{Cartographic Models to Evaluate the Coastal State of Geosystems}

The integrated geo-ecological assessment of the territories at the regional level in relation to their seaside location and specific setup of the 'sea-land' contact zone requires a custom-tailored cartographic approach. In the Kaliningrad region this approach was for the first time implemented with the creation of a geo-ecological map of the region on a scale of 1:200,000. The basic principles of the developers include the fullest reflection of the landscape differentiation of the total area, a cross-spectrum analysis of the component-related and integral indicators, highlighting the areas of the critical geo-ecological situations.

In drawing up the Environmental Safety map, the method of applying the intermediate maps (in the form of layers) concerning the status of individual natural components (soil, vegetation, streams and ponds) and the landscape in general as well as the nature of land use and of anthropogenic impact was used which later became quite promising in computer mapping.

The areas of the most acute environmental situations marked on the map are confined to the urban areas located 
along the Pregolya river valley (Kaliningrad, Chernyakhovsk-Gurievsk) and on the left bank of the river Neman (SovetskNeman). At the same time, some specially protected natural areas including the State National Park Curonian Spit and several nature reserves were allocated. The system continues to be established in the region and is currently far from that shown on the map and representing the historical interest (Zotov et al., 1997).

For highly contaminated attributed condition of the air basin in the cities with the highest density of emissions (230$520 \mathrm{t} / \mathrm{km}^{2}$ xyear) and constantly the pollutants' estimated concentrations exceeding the threshold allowable concentrations. In Kaliningrad the content exceeding the threshold allowable concentration is noted for hydrogen sulphide (in summer), carbon disulphide, benz(a)pyrene (in winter). In some months, an excess of the threshold allowable concentration is noted for heavy metals, i.e. copper, lead, nickel etc. Those areas are referred to as contaminated that have the emission density of 100-200 tons/km²xyear (Krasnoznamensk, Gusev, Pravdinsk). The areas with a density of emissions less than 100 tons $/ \mathrm{km}^{2} \times y e a r$ are characterised as slightly contaminated (Nesterov, Slavsk). Heavily polluted cities tend to have in emissions of the industrial enterprises some specific substances that pose the greatest threat to human health and ecosystems.

For the Kaliningrad region situated in an intense cyclonic activity zone with the frequently repeated air masses coming along the western routes, the long-range transfer of pollutants under the influence of the cross-border transfer from Poland and Germany is very important for creation of the air composition. The high level of contaminant fallout stresses the need to consider cross-border transfer in assessing the changes in trends and forecasting the geoecosystem status.

To determine the stability of the coastal dunes, a special mapping technique based on the integrated indicators, which summarise scores of a status assessment for geosystem components, was developed.

For the coastal waters of the Baltic Sea the map patterns reflected the occurrence and status of invertebrates and phytoplankton, the content of suspended solids, heavy metals and hydrocarbons of the oil series. On the basis of these indicators evaluated were the long-term eutrophication trends of the South-Eastern Baltic waters (the thesis research by T.V. Bukanova), the spatial distribution of oil pollution, by the storm drains of shells of bivalves the areas of the cleanest beaches were identified (Romanchuk).

\section{Simulation Modelling of Hydro Situations and Land-based Geosystem Transformations}

Many years of research by Zotov (2001) in this area are presented in his detailed monograph; so let us only turn our attention to some fundamentally important aspects of this research area. He chose as a subject of research, the Pregolya river basin, the Kaliningrad region's key waterway. Its natural and economic conditions are similar to the river basins in the non-chernozem belts of Russia. The model is built in the lumped parameters for a typical cell of an elementary basin. One year was taken as an interim step due to the model's purpose for the long-term forecasts.

A system of balance equations is used to describe the status of the air environment, vegetation, soil, surface and ground waters. The landscape differentiation in the model is considered in its simplest form, through the division of vegetation cover and soil cover into forest-related and cultural. The natural and anthropogenic impacts are specified through equates.

Numerically the model is implemented by changing the natural and anthropogenic impacts, i.e. the average annual temperature, annual precipitation, annual rate of organic and mineral nitrogen fertilizers introduced in the field, forest cover and drainage conditions of the area. The retrospective experiment for various periods of time proved the acceptable accuracy. The accuracy of the model was evaluated by correspondence of the calculated data to the field data on the dynamics of crop yields, groundwater level and river water flow.

Due to modelling it was possible to quantify the nature of the changes and relaxation time of the geosystem components. For example, the forest phytomass, the content of humus and nitrogen in the soil, the level and flow of groundwater smoothly 'make up' the discontinuous warming and cooling of the climate, and their relaxation time exceeds 100 years. A high response rate of changes in the variables is determined by the long time for their updates, from decades for the groundwater to thousands of years for soil humus. At the same time, the phytomass of the cultivated plants comes to the new climatic conditions during a year. The water depth and flow in the rivers demonstrate spasmodic responses to climate change as well. A change in water availability leads to abruptly varied nitrogen concentrations in water.

Anthropogenic impacts to improve individual performances of geosystems along with the positive effects also cause negative ones. For example, an increase in the amount of nitrogen fertilizers leads to increased crop yields but the ground and surface water pollution is significantly increased as well. An increase in the forest area improves the chemical status of water but an increase in groundwater levels lead to flooding of certain lower areas. 
It is possible to offset the negative consequences through an integrated geosystem approach to optimizing the nature management. As an illustration we hold up the results of experiments in which a combination of external actions was set, an increase in the dose of organic fertilizers by 4 times, forest coverage per cent by 1.5 times and drainage condition by $10 \%$. In this case, all the indicators reflected in the model are improved, e.g. an increase in the phytomass of cultivated plants and the fertility of the soil mantle are accompanied by a decrease in the nitrogen content in the water and a decrease in the groundwater level. Improvement of the hydrochemical composition of water is determined by an increase in the forest area and stabilised fertilizer dressing, the reduced groundwater level or increased drainage conditions, increased soil fertility and crop yields or enhanced organic fertilizer dressing.

\section{Simulation of Urgency of the Geo-ecological Situations in the River Basins}

One of Prof. S.I. Zotov's students N.S. Belov in 2011 in the thesis 'Evaluation of the Geo-Ecological Situation in the Kaliningrad Region's River Basins with the Use of Geographic Information Technologies' (Belov, \& Zotov, 2008) substantiated a new trend in hydro-ecology which can be characterised by an algorithmic approach, not only at the stage of assessment of geosituations but also at the stage of development of the environmental management policy in river basins of the Baltic Sea that have the common catchment area and water area of the flow. Rivers play an increasingly important role in the economic and other human activities and their status largely influence the human welfare. Therefore, the accuracy of the assessment of the hydro-ecological situation in the river basins has an impact on the validity of the adopted economic decisions. Besides the basic indicators it was proposed to use in cartographic modelling a matrix of additional parameters (disturbed lands, topographic features and the economic development factor) and the integral indicator of the situation urgency.

Mapping models with an impressive clarity convincingly demonstrate the urgency of the geo-ecological environments not only in the Kaliningrad region and the Baltic region but also cover basins almost all over Europe. Unfortunately, his main findings are published only in the thesis abstract.

\section{Simulation of the Spatial Differentiation of the Atmospheric Deposition of Heavy Metals}

The long-term studies of the geo-ecological phenomenon determining the cross-border transport of the aerosols of heavy metals in the region and their deposition from the atmosphere to the soil and vegetation cover since 1999 to the present have been performed by Koroleva et al. (2001).

Three massive moss species, Pleurosium shreberi, Hilocomium splendens, Scleropodium purum most effectively concentrate minerals, also from the air and precipitation. Due to the fact that mosses have no root system, it virtually eliminates the contribution from sources other than the atmospheric deposition. Moss samples (a three-year annual growth of plants) were selected at open forest clearings according to a specially developed monitoring method. The metal content was determined by atomic absorption spectroscopy.

Due to the cartographic analysis of the spatial distribution of heavy metals in forest mosses it was possible to develop dependence of contamination of the soil and vegetation cover on the land forms, direction of the wind transfer and precipitation amount. According to the general circulation conditions in the region, for almost a whole year, the surface layers of the atmosphere is dominated by western, south-western and southern winds with the total repeatability from $35 \%$ to $70 \%$. The nature of wind transport is a major factor of the distribution of contaminants throughout the region. On the windward slopes of the hills there is more intense deposition of heavy metals, and in the degradations between large morphostructures 'wind corridors' are created.

The landscape diversity of the region has a significant impact on the distribution and bioaccumulation of heavy metals that deposit from the atmosphere. The research of Yu.V. Koroleva showed it clearly enough. Mosses of the hilly moraine landscapes of the Sambian, Warmia and Vistytis highlands vulnerable under the impact of three factors. Presumably the transfer of heavy metals $(\mathrm{Cr}, \mathrm{Cd}, \mathrm{Cu})$ with atmospheric masses from the Poland and other countries of Western Europe has the highest value compared to the other two, emissions from vehicles and industrial plants.

Mosses of the landscapes of undulating and morainic plains are probably exposed to the industrial centres in Kaliningrad and Chernyakhovsk, oil producing facilities that make a significant contribution to the overall picture of pollution. This type of landscape is characterised by a high content of silver in mosses that can be explained by the crossborder transfer.

The landscape of the glaciolacustrine plains is polluted under the influence of soil erosion, fires on peat bogs, emissions from industrial facilities and cross-border migration from the West-European countries. The latter factor has a significant impact on the distribution of cadmium and copper. 
The ancient alluvial plains, the Sheshupe-Neman interfluve area in the north-east of the Kaliningrad region and the estuary part of the Pregolya river valley differ in the anthropogenic load level. With a factor analysis it was possible to distinguish two components, i.e. the southern part is supposedly exposed to industrial emissions, and the northern part to the fires of peat bogs.

The deltaic landscape near the mouth degradation of the river Neman is also influenced by two factors. Peat fires can influence the excessive accumulation by mosses of $\mathrm{Ni}, \mathrm{Cd}$ and $\mathrm{Mn}$, and the atmospheric aerosol cloud of the Vistula Lagoon can influence the accumulation of $\mathrm{Ag}, \mathrm{Pb}$ and $\mathrm{Cr}$.

The coastal-marine landscapes are subjected to the active influence of marine aerosols coming from the Baltic Sea; $\mathrm{Zn}, \mathrm{Mn}, \mathrm{Fe}$ and $\mathrm{Cu}$ are deposited with the precipitation here.

Due to the factor analysis it was possible to characterise the Kaliningrad region's sources of contamination in 1994-2005. (Barinova et al., 2012). During that time, the load on the biosystem changed significantly; the deposition of heavy metals considerably decreased in Europe. A further assessment of the contributions from various sources and cross-border transport of pollutants are required for a sound strategy of the Kaliningrad region's development in the field of land use, environmental protection and public health.

\section{Mapping Models of Storm Floods}

Based on the initial 60-year data (1950-2009) on the maximum annual values of the water level in the estuary of the river Pregolya (Kaliningrad Sea Fishery Port), historical and geographical information about the dynamics of storm floods in Koenigsberg (Kaliningrad) during XVI-XX centuries, O.E. Lyubimova performed a thesis research and published the outcomes of cartographic modelling of one of the most dangerous natural process to the region's capital taking into account the risk of flooding of industrial and civil companies as well as the economic damage inevitable in such cases (Krasnov, \& Lyubimova, 2000).

The mapping models of critical and catastrophic situations were developed with the use of Digitals and Micro Station software based on digital terrain maps of the wellhead area. The empirical and statistical processing of the initial data was based on understanding of the unsteadiness and inhomogeneity of storm flooding. The inter-annual dynamics of the maximum increase in the river water level in the mouth was studied as a probabilistic and deterministic process which includes the main trend, i.e. the cyclical component and random (residual) fluctuations.

The empirical and statistical analysis of water level fluctuations in the estuary of the river Pregolya showed a positive linear level growth trend in 60 years by $40 \mathrm{~cm}$. From 1950 to 2009 the relative frequency of exceeding a particularly dangerous level of $+155 \mathrm{~cm}$ (in the Baltic system) increased by 4 times, and the frequency exceeding the level of $+95 \mathrm{~cm}$ by 1.5-2 times. At the same time, the frequency of exceeding the level of $+180 \mathrm{~cm}$ remained unchanged. All values obtained with a reliable 10 -fold increase of $1 \%$ probability that the rightly points to the urgent need for the development and implementation of preventive measures to reduce the risk of significant potential impacts (economic, environmental and social) from the storm floods in the centre of Kaliningrad (Krasnov, \& Lyubimova, 2005).

The alternation of various height levels and the scope of their variation in amplitude led to the conclusion that the process was cyclical (multi-ordinal). Graphically, most clearly expressed is the 16-18-year cyclicity correlated with the water content (flow) of the rivers of the western regions of Russia and Ukraine (Moskalets, \& Lyubomova, 2013). . From this it is also possible to make a hypothesis of the 35-year cyclicity linked to various surface air temperature, precipitation and pressure as well as alternating phases of the climatic moisture and heat supply. Taking the hypothesis concerning the flood cyclicity as the basis for forecasting, the researchers came to the conclusion of the likelihood of the following extreme storm flooding in the mouth area of the river Pregolya in 2016-2018 with an increase in the critical level of 155 $\mathrm{cm}$ of the Baltic elevation system (BS) and even the catastrophic values of $+180 \mathrm{~cm}$ of BS. Based on the digital topographic map of the contour lines and elevations in the triangulation form, the authors (Krasnov, \& Lyubomova, 2013.) presented a digital model of the flooding area in the valley of the river Pregolya within the city limits for the seven stages of flood spread.

Cartographic modelling will no doubt continue to develop successfully in the Institute of Nature Management, Spatial Planning and Urban Development as one of the most promising areas of geography and geo-ecology.

\section{References}

Barinova, G.M., Korolleva, Yu.V., \& Krasnov, E.V. (2012). Indicative Modelling and Spatial Evaluation of Air Pollution Risk. Risk Models and Applications (pp 23-34): Collected Papers/Eds: Horst Kremers, Alberto Susini. CODATA-Germany e.V.

Barinova, G.M., Zotov, S.I., \& Kochurov, B.I. (1994). The Coastal Area Environmental Mapping Experience (Kaliningrad Region). 
Proceedings of the Russian Geographical Society. V. 126. Issue 6, 50-58.

Basaliskas, A.B. (1921) Landscape and Typological Map Atlas of the Lithuanian SSR, M.: Publishers of the Main Department of Geodesy and Cartography.

Belov, N.S., \& Zotov, S.I.(2008). Assessment of the Hydro-Ecological Status of the Kaliningrad Region's River Systems. Newsletter of the I. Kant RSU. Issue 1, 6-16.

Blazchishin, A.I., \& Krasnov, E.V.(1998). On the Silver Concentrations in the Sediments of the Gotland Basin. Reports of the Russian Academy of Sciences. Volume 361, No 4, 527-530.

Dedkov, V.P., \& Fedorov, G.M. (2006). The Spatial, Territorial and Landscape Planning in the Kaliningrad Region. Kaliningrad: Publishers of the I. Kant RSU.

Geographical Atlas to the Kaliningrad Region. Kaliningrad: Publishers of the KSU; Scientific and Technological Information Centre. $276 \mathrm{p}$.

Kavalyauskas, P.O. (1976). On the Landscape Arrangement Factors. Geography of Lithuania: Collected Papers, Vilnius.

Koroleva, Yu.V., Barinova, G.M., \& Pukhlova, I.A. (2009). The Use of GIS Technologies for the Assessment of Transboundary Transport of Heavy Metals (pp 567-581): Interkarto/InterG/S - 15. Perm.

Koroleva, Yu.V., Krasnov, E.V., \& Gorinova, G.V. (2001) Bioindication of Air Pollution by Heavy Metals on the Sambian Peninsula. Environmental Problems of the Kaliningrad Region and the Baltic Region: Collected Research Papers (pp 37-42). Kaliningrad, Publishers of the Kaliningrad State University.

Kozlovich, I.I. (2006). Landscape-Ecological Research into the Curonian Spit (a look back analysis). Newsletter of the I. Kant RSU. Issue $1,22-27$.

Krasnov, E.V., \& Lyubimova O.E. (2005). Digital Mapping of Geo-Ecological Situations and Flooded Area Simulation in the Coastal Area. Works of the international research-to-practice conference The Problems Associated with the Management of the Social and Economic Issues of the Region (pp 99-102) . Kaliningrad: Kaliningrad Higher School of Management.

Krasnov, E.V., \& Lyubimova, O.E. (2000). Multifactor Environmental Emergency Risk Assessment in the Kaliningrad region. Newsletter of the KSU. Issue 2, 90-98.

Krasnov, E.B., \& Lyubomova, O.E. (2013.) Geosystem Approach to Assessing the Storm Flood Risks in the Mouth of the River Pregolya, Kaliningrad Region. Regional Environment, 2 (34), 15-22.

Lyubomova, O.E., \& Krasnov, E.V. (2006). Cartographic Modelling of the Critical Situations in the Coastal-Marine Areas. Geo-Ecology, Engineering Geology, Hydroecology, Geocryology. № 3, 242-250.

Moskalets, V.F., \& Lyubomova, O.E. (2013). More on the Forecast of Extreme Floods in Kaliningrad. Local Government and Municipal Staff Training: Status, Problems: Collection of Articles (pp 129-134). Kaliningrad: the Baltic Institute of Economics and Finance.

State Reports on the Environmental Situation in the Kaliningrad Region in 2011, 2012, 2013

Stauskas, V.P. (1987). Town-Planning Arrangements for Recreational Areas and Centres. L.

Volkova, I.I., \& Korneevets, L.V. (2002) Landscape Maps of the Baltic (Vistula) and Curonian Spits. Geographical Atlas of the Kaliningrad Region (pp 76-77). Kaliningrad: Publishers of the KSU; Scientific and Technological Information Centre.

World Atlas: Volume 20: Kaliningrad region (2011).

Yemelyanov, E.M. (1993). Geo-Ecological Research (outcomes, problems). Newsletter of the Baltic Research Centre. № 1, 20-24.

Zagorodnykh, V.A. (2001). Stratigraphy and Mineral Resources of the Quaternary Deposits of the Kaliningrad Region. Domestic Geology. № 3, 45-56.

Zotov, S. I. (2001). Geosystem Status Modelling: Training Manual. Kalinngrad.

Zotov, S.I., \& Krasnov, E.V., \& Barinova, G.M. (1997) Programme for Improvement of the Ecological Situation in the Baltic Sea (Kaliningrad Region). Problems of the Regional Ecology. No 1, 87-98. 